\title{
A Quantitative Study on Attitudes of Web-Based Mathematic Competition in Different Learning Stages Students in Taiwan
}

\author{
doi:10.3991/ijet.v4i2.697 \\ Tai-Cheng Tso, Feng-Kuang Chiang, Hsin-Chang Lu, Chung-Shan Sun \\ National Kaohsiung Normal University
}

\begin{abstract}
The study mainly investigates the students' attitudes toward mathematic learning and web-based mathematic competition in different learning stages in Taiwan. This study was to conduct an online survey, which is driven by three issues: (1) What are the differences in mathematical learning attitudes with the web-based mathematics competition in the different learning stages (2) Is there any significant difference between students' mathematical learning attitudes to take part in the webbased mathematics competition in the different learning stages? (3) Is there any correlation between students' mathematical learning attitudes, the participators' motivation and the attitudes of students' took part in the web-based mathematics competition? The research targets of this study are 277 students, including $207(74.7 \%$ ) boys and $70(25.3 \%)$ girls. The collected data of this study was analyzed by descriptive statistics, one-way ANOVA, Scheffe' method and Pearson's product-moment correlation. Following are the results of the study: There is significant motivational difference between elementary school and junior high school students to participate the web-based mathematic competition and there are middle relationships between students' mathematical learning attitudes, the participators' motivation and the attitudes of students' took part in the web-based mathematics competition.
\end{abstract}

Index Terms-Web-Based Mathematics Competition, Participator Attitudes

\section{INTRODUCTION}

More and more technologies like mobile-learning, elibrary or virtual learning environment are cropping up around the world and challenging traditional teaching materials; anyone can get information and share knowledge through the WWW easily. The rapid development of the everywhere-accessible Internet has caused certain changes to instructional forms [1](Lee, Yeh, Kung , \& Hsu, 2007). [2]Harold (2006) pointed out the integration of new information technology into society as a whole and into the educational environment in particular seems destined to increase. In the age of Internet and information, the education is moving toward to a teaching and learning evolution. Technology of information provides easy access to mathematic for all students. In addition, the way of competition coheres with the principle of interest and the self-learning in teaching method arousing the interests and attentions of the competitors. Taiwan participated in many international competitions with outstanding performance such as
International Mathematical Olympiad (IMO), Asian Pacific Mathematics Olympiad (APMO), and Po Leung Kuk Primary Mathematics World Competition (PMWC). However, not everyone has the opportunity to join the competitions. It is the authority of specific students or phenom. Furthermore, the entries for IMO and APMO are high school students, even though there some competitions are held in Japan, Indonesia, India, Mainland China (including Hong Kong) for primary school, and junior high. These are still unavailable to every student. If we hold an activity for any grades, it would greaten the opportunities for every student to communicate on mathematic. As a consequence, this year, 2006.9 2007.2, a general web-based competition was opened for K1-K12 student through internet in Taiwan [3] (Chiang, Lu, Tso, \& Sun, 2008).

The study mainly explored students' mathematic learning attitudes and opinions not only provide the references in the next competition but also understand students' thinking deeply. The study mainly investigates the students' attitudes toward mathematical learning and web-based mathematics competition in different learning stages in Taiwan. The questions of this study are as follows: (1) What are the differences in the mathematical learning attitudes with the web-based mathematics competition in the different learning stages (2) Is there any significant difference between students' mathematical learning attitudes to take part in the web-based mathematics competition in the different learning stages? (3) Is there any correlation between students' mathematical learning attitudes, the participators' motivation and the attitudes of students' took part in the web-based mathematics competition?

\section{LITERATURE REVIEW}

Competition is good as long as the students are not having a permanent "lose", which would lead to dissatisfaction [4] (Van Eck, 2006). And also it is a kind of learning and Competitive Strategy. Past research has found that web-based mathematic competition can help students (1) to creative the fun of mathematical learning, (2) to reduce the pressure of mathematical learning, (3) to promote their thinking and recall the mathematical knowledge, (4) to understand their mathematical abilities, and (5) to create a self-learning and mathematic learning achievement [3]. [5]Ozturk \& Debelak (2008) point out that there is no doubt that academic competitions can serve as strong motivators for students by providing an incentive to study and work hard so they can be ready to 
compete at a certain level. And they believe that it can provide students with excellent opportunities to develop in many ways, including intrinsic and extrinsic motivation [6] (Lepper, Corpus, \& Iyengar, 2005) as well as the nurture of a healthy self-concept. The competition process in which children strive to realize their intellectual or talent potential is an important part of gathering selfconfidence and self-awareness [7] (Rogers, 1959). [8] Nur Azyan, Yusof, \& Suraya (2007) pointed out that the development of mathematical web-based system helps to strengthen the position of Information and Communication Technology (ICT) in the society by increasing the Internet usage towards educational pursuit by the students. These advantages that mathematic webbased system has been discovered are as follow: Flexibility, Delivery Method, Speed of Learning, Teaching Tools and Materials, Competition Environment, and Progress Tracking (see Table 1).

TABLE I.

COMPARISON SUMMARY BETWEEN THE TRADITIONAL TEACHING MODE AND MATH-WEBSC

\begin{tabular}{|l|l|l|}
\hline \multicolumn{1}{|c|}{$\begin{array}{c}\text { Advantages } \\
\text { features }\end{array}$} & \multicolumn{1}{|c|}{$\begin{array}{c}\text { Traditional } \\
\text { teaching }\end{array}$} & \multicolumn{1}{|c|}{ Math-WebSC } \\
\hline Flexibility & Bounded & Not bounded \\
\hline Delivery method & Teacher-centered & Student-centered \\
\hline Speed of learning & Teacher-paced & Student self-paced \\
\hline $\begin{array}{l}\text { Teaching tools } \\
\text { and materials }\end{array}$ & $\begin{array}{l}\text { 2D and static } \\
\text { blackboard and } \\
\text { paper }\end{array}$ & $\begin{array}{l}\text { Online 3D graphics, } \\
\text { interactive elements }\end{array}$ \\
\hline $\begin{array}{l}\text { Competition } \\
\text { Environment }\end{array}$ & $\begin{array}{l}\text { Competing among } \\
\text { peers }\end{array}$ & Self-compete \\
\hline Progress tracking & $\begin{array}{l}\text { Manually by } \\
\text { teachers }\end{array}$ & $\begin{array}{l}\text { Automatically by } \\
\text { the system }\end{array}$ \\
\hline
\end{tabular}

Source: Nur Azyan, Yusof, \& Suraya, (2007). Mathematic Web-Based System as Students' Study Companion: A Scenario in Malaysia. The International Journal of Learning. 14 (9). 205-213.

[9] Nguyen (2002) contrasted the achievement of students using the web-based assisted-learning-and assessment (WALA) with the achievement of students using the traditional paper-and-pencil assessment and practice (TALA). Students in the WALA group believed that web-based mathematic assessment offers them more control over their work and helps them to improve their confidence in mathematic problem solving. In addition, [10] Nguyen, Yi-Chuan, \& Allen (2006) investigated the effects of web-based assessment and practice on improving middle school students' mathematic learning attitudes. They found that web-based assessment and practice tool substantially helps students in building motivation and elevates the meaning of learning and doing mathematic with the use of web-based technology. Based on the literature review, we can know the web-based mathematical competition can promote students' mathematical learning and one kind of meaningful learning.

\section{RESEARCH DESIGN}

\section{A. Web-based Mathematic Competition System (Web- based MCS)}

Figure 1 illustrates the framework of the research design. There are three different learning stage students who took part in this web-based math competition. Researchers attempted to explore the relation between mathematical learning attitudes and web-based mathematics competition in the different learning stage students.

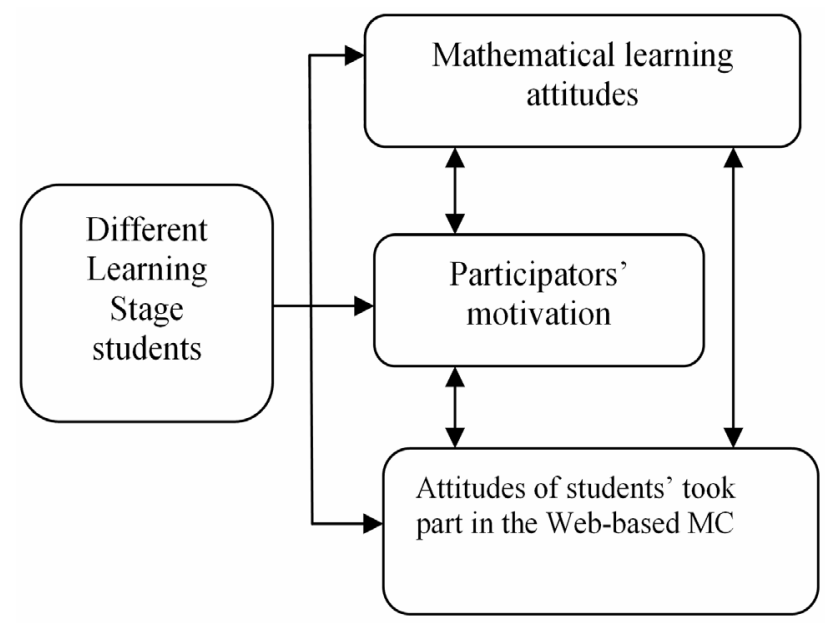

Figure 1. The framework of research design

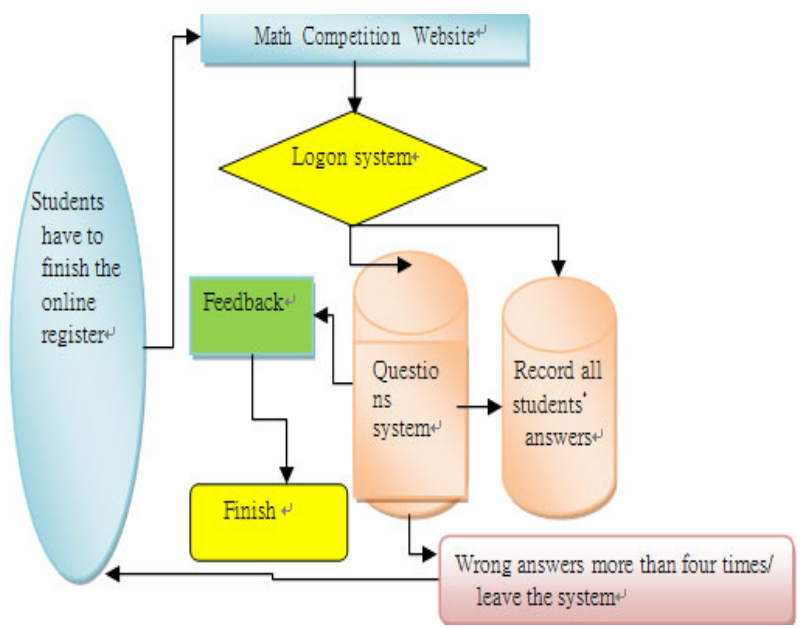

Figure 2. The process of students took part in Web-based MCS

Figure 2 shows the process of students took part in web-based MCS. First, students have to register personal information on this website, and then they can logon the web-based MCS to exam the four different levels mathematical questions. The Web-based MCS will provide the feedback and record the process of how students answer these questions. Once participators answer the wrong for four times, they will be logged off by the system automatically.

\section{B. The design of questionnaire}

The main questionnaire items are a revised version of of Nguyen's questionnaire of a web-based mathematical instruction and assessment on student achievements and attitudes. There are four experts in related fields, who reviewed these questions after redesigning the questionnaire. This questionnaire has 25 questions. The questionnaire investigates the students' attitude toward the mathematical learning and web-based mathematics competition. The questionnaire took the Likert's Scale 1-5, the questionnaire asked the students to select one answer form the choice of "Very Agree," "Agree", "No 
comment", "Disagree", and "Very Disagree" according to their opinions. These scale is also given by numbers 5,4 , 3, 2, 1 scores respectively. The Cronbach Alpha reliability coefficient of the questionnaire is 0.907 , well over 0.8 , indicating a high reliability.

\section{Data collection and analysis}

This study was to conduct an online survey, and participators can fill out the questionnaire survey freely. The research targets of this study are 277 students, including $207(74.7 \%)$ boys and $70(25.3 \%)$ girls. The collected data of this study was analyzed by descriptive statistics such as one-way ANOVA, the Scheffe' method, and Pearson's product-moment correlation.

\section{FINDINGS}

There are 57 elementary school students, 126 junior high school students, and 94 senior high school students who fill out the online questionnaire.

\section{A. Learning attitudes of different stages}

Here, the mathematical learning attitudes with the webbased mathematic competition in the different learning stages are compared. Figures 3, 4, and 5 show the mean of three variables (attitudes of mathematical learning, motivations of Web-based MC, attitudes of students took part in the Web-based MC) in the different learning stages. Figure 3 shows that elementary school students own high mathematical learning attitudes than other two learning stages. Senior high school students have the lowest mathematical learning attitudes. Thus, attitudes of mathematical learning get lower and lower with rising learning stages. There are the highest mean among three variables on elementary school students. Interestingly, the mean drop from elementary school to junior high school is much more significant than the one from junior high school to senior high school. This phenomenon is discussed in the next section.

Besides, there is similar curve between figure 4 and figure 5. This suggests that there might be a relation between motivations of web-based MC and attitudes of students took part in the web-based MC. The authors tried to analyze the curves in figure 4 and 5 and answer the question, why junior high school students are also the lowest mean as follows: Junior high school learning stage is a kind of turn point between elementary and senior high school result in learner have to adapt the different instructional styles and academic pressure. Senior high school students are the lowest attitudes of mathematical learning; the math is the difficult subject so that the result.

\section{B. Statistical analyses}

There is significant difference between elementary school and junior high school students on the motivations of web-based MC.

As shown in the table 2, we can know as follows:

1) About the attitudes of mathematical learning variable $(\mathrm{F}=2.858 \mathrm{P}>.05)$, it is not a significant difference among the different learning stage students.

2) According the motivations of web-based $\mathrm{MC}$ $(\mathrm{F}=4.470 \mathrm{P}<.05)$, on the other hand, there is significant different among the different learning stage students. Therefore, the data will be retested the difference by Scheffe' method (see table 3).

3) According the attitudes of students, who took part in the web-based $\mathrm{MC}(\mathrm{F}=1.494 \mathrm{P}>.05)$, there is no significant difference among the different learning stage students.

According to the table 3, it is indicated that elementary school students have higher motivated to take part in the web-based MC than junior high school students.

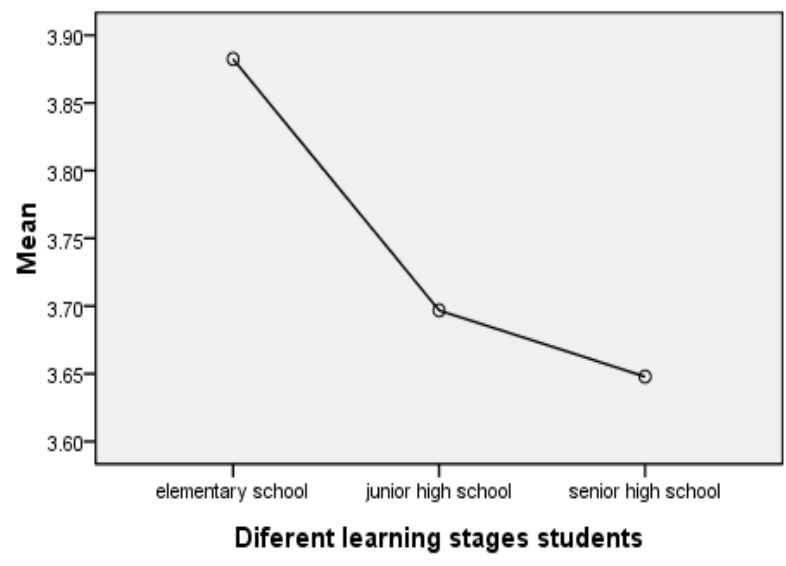

Figure 3. Attitudes of mathematical learning

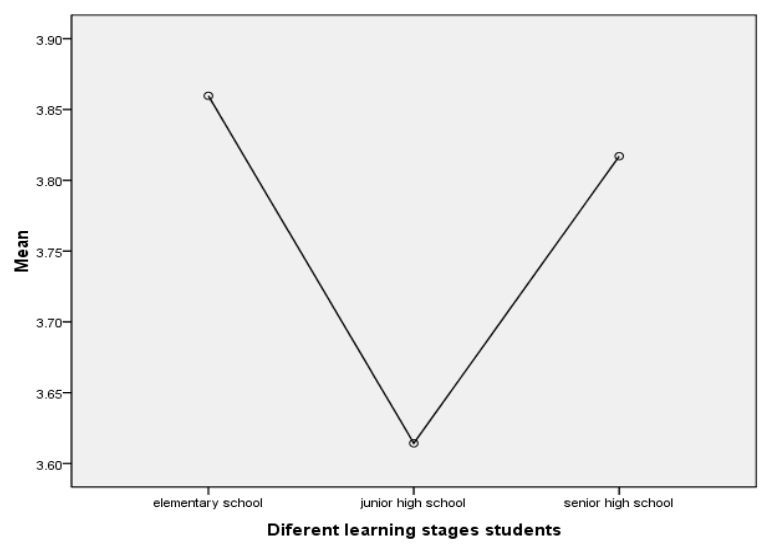

Figure 4. Motivation of Web-based MC

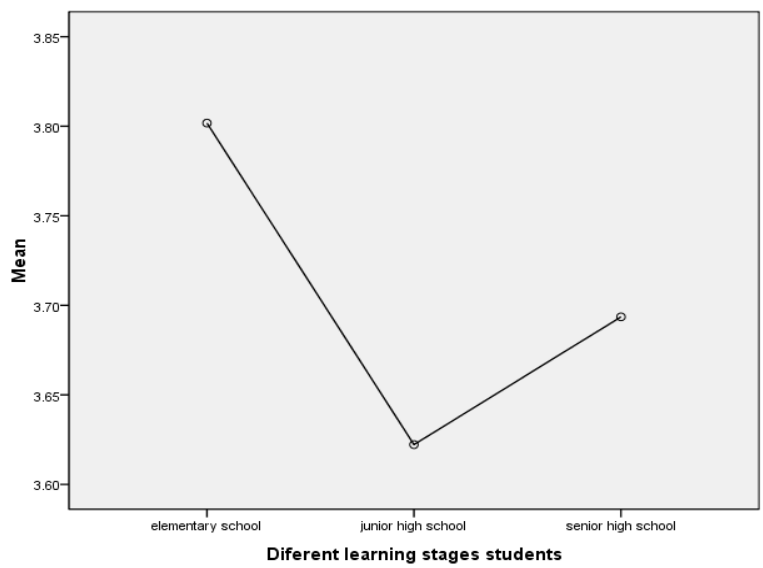

Figure 5. Attitudes of Students, who took part in the Web-based MC 
TABLE II. ANOVA

\begin{tabular}{|c|c|c|c|c|c|c|}
\hline & & $\begin{array}{l}\text { Sum of } \\
\text { Squares }\end{array}$ & df & $\begin{array}{l}\text { Mean } \\
\text { Square }\end{array}$ & $\mathbf{F}$ & Sig. \\
\hline \multirow{3}{*}{$\begin{array}{l}\text { Attitudes of } \\
\text { mathematical } \\
\text { learning }\end{array}$} & $\begin{array}{l}\text { Between } \\
\text { Groups }\end{array}$ & 2.060 & 2 & 1.030 & \multirow[t]{3}{*}{2.858} & \multirow[t]{3}{*}{.059} \\
\hline & $\begin{array}{l}\text { Within } \\
\text { Groups }\end{array}$ & 98.776 & 274 & .360 & & \\
\hline & Total & 100.836 & 276 & & & \\
\hline \multirow{3}{*}{$\begin{array}{l}\text { Motivations } \\
\text { of Web- } \\
\text { based MC }\end{array}$} & $\begin{array}{l}\text { Between } \\
\text { Groups }\end{array}$ & 3.354 & 2 & 1.677 & \multirow[t]{3}{*}{4.470} & \multirow[t]{3}{*}{$.012 *$} \\
\hline & $\begin{array}{l}\text { Within } \\
\text { Groups }\end{array}$ & 102.784 & 274 & .375 & & \\
\hline & Total & 106.138 & 276 & & & \\
\hline \multirow{3}{*}{$\begin{array}{l}\text { Attitudes of } \\
\text { Students } \\
\text { took part in } \\
\text { the Web- } \\
\text { based MC }\end{array}$} & $\begin{array}{l}\text { Between } \\
\text { Groups }\end{array}$ & 1.280 & 2 & 640 & \multirow[t]{3}{*}{1.494} & \multirow[t]{3}{*}{.226} \\
\hline & $\begin{array}{l}\text { Within } \\
\text { Groups }\end{array}$ & 116.904 & 274 & \multirow[t]{2}{*}{.428} & & \\
\hline & Total & 118.183 & 276 & & & \\
\hline
\end{tabular}

*. The mean difference is significant at the 0.05 level.

TABLE III.

SCHEFFE' MULTIPLE COMPARISONS

\begin{tabular}{|c|c|c|c|c|c|c|c|}
\hline \multirow[b]{2}{*}{$\begin{array}{c}\text { Dependent } \\
\text { Variable }\end{array}$} & \multirow{2}{*}{$\begin{array}{l}\text { (I) } \\
\text { Gro } \\
\text { up }\end{array}$} & \multirow{2}{*}{$\begin{array}{l}\text { (J) } \\
\text { Gro } \\
\text { up }\end{array}$} & \multirow{2}{*}{$\begin{array}{c}\text { Mean } \\
\text { Difference } \\
\text { (I-J) }\end{array}$} & \multirow[b]{2}{*}{$\begin{array}{l}\text { Std. } \\
\text { Error }\end{array}$} & \multirow[b]{2}{*}{ Sig. } & \multicolumn{2}{|c|}{$\begin{array}{c}95 \% \\
\text { Confidence } \\
\text { Interval }\end{array}$} \\
\hline & & & & & & \begin{tabular}{|l|} 
Lower \\
Bound
\end{tabular} & $\begin{array}{l}\text { Upper } \\
\text { Bound }\end{array}$ \\
\hline \multirow{6}{*}{$\begin{array}{l}\text { Attitudes of } \\
\text { mathematic } \\
\text { learning }\end{array}$} & \multirow{2}{*}{ E } & J & .18563 & .09584 & .155 & -.0503 & .4215 \\
\hline & & $\mathrm{S}$ & .23458 & .10079 & .068 & -.0135 & .4827 \\
\hline & \multirow{2}{*}{$\mathrm{J}$} & $E$ & -.18563 & .09584 & .155 & -.4215 & .0503 \\
\hline & & $\mathrm{S}$ & .04895 & .08183 & .836 & -.1524 & .2504 \\
\hline & \multirow{2}{*}{ S } & $\mathrm{E}$ & -.23458 & .10079 & .068 & -.4827 & .0135 \\
\hline & & $\mathrm{J}$ & -.04895 & .08183 & .836 & -.2504 & .1524 \\
\hline \multirow{6}{*}{$\begin{array}{l}\text { Motivation } \\
\text { s of Web- } \\
\text { based MC }\end{array}$} & \multirow{2}{*}{ E } & $\mathrm{J}$ & $.24536^{*}$ & .09777 & .044 & .0047 & .4860 \\
\hline & & $\mathrm{S}$ & .04263 & .10282 & .918 & -.2104 & .2957 \\
\hline & \multirow{2}{*}{$\mathrm{J}$} & $\mathrm{E}$ & $-.24536^{*}$ & .09777 & .044 & -.4860 & -.0047 \\
\hline & & $\mathrm{S}$ & -.20274 & .08347 & .054 & \begin{tabular}{|l|}
-.4082 \\
\end{tabular} & \begin{tabular}{|l|}
.0027 \\
\end{tabular} \\
\hline & \multirow{2}{*}{ S } & E & -.04263 & .10282 & .918 & -.2957 & .2104 \\
\hline & & $\mathrm{J}$ & .20274 & .08347 & .054 & -.0027 & .4082 \\
\hline \multirow{6}{*}{$\begin{array}{l}\text { Attitudes of } \\
\text { Students } \\
\text { take part in } \\
\text { the Web- } \\
\text { based MC }\end{array}$} & \multirow{2}{*}{ E } & $\mathrm{J}$ & .17953 & .10446 & .230 & \begin{tabular}{|l|}
.0776 \\
\end{tabular} & .4366 \\
\hline & & S & .10821 & .11008 & .617 & -.1627 & .3791 \\
\hline & \multirow{2}{*}{$\mathrm{J}$} & E & -.17953 & .10446 & .230 & -.4366 & .0776 \\
\hline & & $\mathrm{S}$ & -.07133 & .08946 & .728 & -.2915 & .1489 \\
\hline & & $\mathrm{E}$ & -.10821 & .11008 & .617 & -.3791 & .1627 \\
\hline & & $\mathrm{J}$ & .07133 & .08946 & .728 & \begin{tabular}{|l|}
-.1489 \\
\end{tabular} & .2915 \\
\hline
\end{tabular}

*. The mean difference is significant at the 0.05 level.

Notes: E=Elementary school, J=Junior high school, $\mathrm{S}=$ Senior high school

\section{Relation among selected variables}

Next, we analyzed the relation among the selected variables and derived the result shown in table 4 . Obviously, there is medium relation among selected variables. As shown in table 4, the correlations are $.578, .585$ and .631 among the three variables. Thus, among these three variables there are still medium correlations with each other. These results are similar than the ones shown in the figure 4 , and 5.
TABLE IV. CORRELATIONS

\begin{tabular}{|c|c|c|c|c|}
\hline & & \begin{tabular}{|c|} 
Attitudes \\
of \\
mathemat \\
ical \\
learning
\end{tabular} & $\begin{array}{c}\text { Motivations } \\
\text { of Web- } \\
\text { based MC }\end{array}$ & $\begin{array}{l}\text { Attitudes of } \\
\text { Students } \\
\text { take part in } \\
\text { the Web- } \\
\text { based MC }\end{array}$ \\
\hline \multirow{3}{*}{$\begin{array}{l}\text { Attitudes of } \\
\text { mathematic } \\
\text { al learning }\end{array}$} & \begin{tabular}{|l|} 
Pearson \\
Correlation
\end{tabular} & 1.000 & $.578 * *$ & $.585^{* *}$ \\
\hline & Sig. (2-tailed) & & .000 & .000 \\
\hline & $N$ & 277.000 & 277 & 277 \\
\hline \multirow{3}{*}{$\begin{array}{l}\text { Motivations } \\
\text { of Web- } \\
\text { based MC }\end{array}$} & \begin{tabular}{|l} 
Pearson \\
Correlation
\end{tabular} & $.578 * *$ & 1.000 & $.631 * *$ \\
\hline & Sig. (2-tailed) & .000 & & .000 \\
\hline & $N$ & 277 & 277.000 & 277 \\
\hline \multirow{3}{*}{$\begin{array}{l}\text { Attitudes of } \\
\text { Students } \\
\text { take part in } \\
\text { the Web- } \\
\text { based MC }\end{array}$} & \begin{tabular}{|l} 
Pearson \\
Correlation
\end{tabular} & $.585 * *$ & $.631 * *$ & 1.000 \\
\hline & Sig. (2-tailed) & .000 & .000 & \\
\hline & $N$ & 277 & 277 & 277.000 \\
\hline
\end{tabular}

**. Correlation is significant at the 0.01 level (2-tailed).

\section{CONCLUSIONS}

The main purpose of this study is to investigate and analyze the students' attitudes toward mathematical learning and web-based mathematics competition in different learning stages in Taiwan. Findings from this study provide some results as follows.

There is a significant difference between elementary school and junior high school students on the motivations of web-based MC. Elementary school students have higher motivations of web-based MC than junior high school students.

There is a medium relation among selected variables (attitudes of mathematical learning, motivations of webbased MC, and attitudes of students took part in the Webbased MC).

For this reason, authors infer that the attitude toward the mathematical learning will affect the motivation of Webbased MC, and thus, affecting their attitude toward webbase mathematics competition.

Finally, authors advance the research limitations and future works. This might have accounted for the low response rate of the surveys; researchers suggest designing some draw lots or strategies in the next survey in order to increase a high response rate.

In the future works, the authors will analyze the processes of how students solve the mathematical questions and then the web-based MC system will be improved the faction in the future.

\section{ACKNOWLEDGMENT}

The authors greatly appreciate the financial support provided by Taiwan's National Science Council, the Republic of China under contract No. 95-2515-S-017-001.

\section{REFERENCES}

[1] Lee, C. H., Yeh, D., Kung R. J., \& Hsu, C. S. The Influences of Learning Portfolios and Attitudes on Learning Effects in Blended E-learning for Mathematic. Journal of Educational Computing Research. 37(4). Pp. 331-250, 2007. (doi:10.2190/EC.37.4.a) 
[2] Harold, R.. Information Technology integration in higher education: A case study of historically black university. Unpublished doctoral dissertation, Capella University, 2006.

[3] Chiang, F. K., Lu, H. C., Tso, T. C., \& Sun, C. S. An Investigation on Students Participate in 2006 Web-based Mathematic Competition: Taiwan Experience. GCCCE 2008 (12th Global Chinese Conference of Computer in Education). May 4 8, Michigan, USA. Beijing Normal University Press, 2008.

[4] Van Eck, R. The Effect of Contextual Pedagogical Advisement and Competition on Middle-School Students' Attitude toward Mathematics and Mathematics Instruction Using a ComputerBased Simulation Game. Journal of Computers in Mathematic and Science Teaching, 25(2), pp. 165-195, 2006.

[5] Ozturk, M. A. \& Debelak, C. Affective Benefits from Academic Competitions for Middle School Gifted Students. Gifted Child Today, 31(2), pp. 48-53, 2008.

[6] Lepper, M. R., Corpus, J. H., \& Iyengar, S. S. Intrinsic and extrinsic motivational orientations in the classroom: Age differences and academic correlates. Journal of Educational Psychology, 97,pp. 184-196, 2005. (doi:10.1037/00220663.97.2.184)

[7] Rogers, C., A theory of therapy, personality, and interpersonal relationships, as developed in the client centered framework. In S. Koch (Ed.), Psychology: A study of a science (Vol. 3, pp. 184256). New York: McGraw-Hill, 1959.

[8] Nur Azizan@ Nur Azyan Yusof, \& Suraya, H. Mathematics Web-Based System as Students' Study Companion: A Scenario in Malaysia. The International Journal of Learning. 14 (9).pp. $205-$ 213, 2007.

[9] Nguyen, D. M. Developing and evaluating the effects of Webbased mathematic instruction and assessment on student achievement and attitude. Dissertation Abstracts International, 63(8), 2782A. (UMI No. AAT 3060864), 2002.

[10] Nguyen, D M., Yi-Chuan J. H., \& Allen, D. The Impact of WebBased Assessment and Practice on Students' Mathematic Learning Attitudes. Journal of Computers in Mathematic \& Science Teaching, 25(3), pp. 251-279, 2006.

\section{AUTHORS}

Tai-Cheng Tso (e-mail: taicheng@nknucc.nknu.edu.tw) is a professor in the Department of Mathematics at at the National Kaohsiung Normal University, Taiwan

Feng-Kuang Chiang (e-mail: forite@gmail.com) is a Doctor Student in the Department of Industrial Technology Education at the National Kaohsiung Normal University, Taiwan.

Hsin-Chang Lu (e-mail: lu@nknucc.nknu.edu.tw) is a Doctor Student in the Department of Industrial Technology Education at the National Kaohsiung Normal University, Taiwan.

Chung-Shan Sun (e-mail: x9106@ms21.hinet.net) is a Professor in the Department of Industrial Technology Education at the National Kaohsiung Normal University, Taiwan.

Manuscript received 15 October 2008. Published as submitted by the authors. 